\title{
Primary hyperparathyroidism-related giant parathyroid adenoma (Review)
}

\author{
ADINA GHEMIGIAN $^{1,2}$, ALEXANDRA IOANA TRANDAFIR ${ }^{2}$, EUGENIA PETROVA ${ }^{1,2}$, MARA CARSOTE $^{1,2}$, \\ ANA VALEA $^{3,4}$, ALEXANDRU FILIPESCU ${ }^{5,6}$, ANA-MARIA OPROIU ${ }^{7,8}$ and FLORICA SANDRU ${ }^{9,10}$ \\ ${ }^{1}$ Department of Endocrinology, 'Carol Davila' University of Medicine and Pharmacy, 050474 Bucharest; \\ ${ }^{2}$ Department of Endocrinology, 'C.I. Parhon' National Institute of Endocrinology, 011863 Bucharest; \\ ${ }^{3}$ Department of Endocrinology, 'I. Hatieganu' University of Medicine and Pharmacy, 400012 Cluj-Napoca; \\ ${ }^{4}$ Department of Endocrinology, Clinical County Hospital, 400000 Cluj-Napoca; ${ }^{5}$ Department of \\ Obstetrics and Gynecology, 'Carol Davila' University of Medicine and Pharmacy, 050474 Bucharest; \\ ${ }^{6}$ Department of Obstetrics and Gynecology, 'Elias' Emergency University Hospital, 011461 Bucharest; \\ ${ }^{7}$ Department of Plastic and Reconstructive Surgery, 'Carol Davila' University of Medicine and Pharmacy, \\ 050474 Bucharest; ${ }^{8}$ Department of Plastic and Reconstructive Surgery, University Emergency Hospital, \\ 050098 Bucharest; 'Department of Dermatology, 'Carol Davila' University of Medicine and Pharmacy, \\ 050474 Bucharest; ${ }^{10}$ Department of Dermatology, 'Elias’ Emergency Hospital, 011461 Bucharest, Romania
}

Received August 6, 2021; Accepted September 7, 2021

DOI: $10.3892 /$ etm.2021.11011

\begin{abstract}
Primary hyperparathyroidism (PHPT), an endocrine condition caused by a parathyroid adenoma (PTA) in $80-85 \%$ of the cases, has shifted in the modern era to a mildly symptomatic phenotype due to the prompt recognition of hypercalcemia and to a minimally invasive surgical approach which has a curative potential. Clinical complications of PHTH are either related to high calcium or parathyroid hormone [also parathormone (PTH)] or both, while the originating tumor typically is small, without local mass effects. A distinct entity is represented by giant PTA (GPTA) which is considered at a weight of more than 3 (3.5) grams. The present article is a review of the literature involving practical points of non-syndromic PHPT-related GPTA. Most authors agree that pre-operatory calcium and PTH are higher in GPTA vs. non-GPTA. However, the clinical presentation of PHPT may be less severe, probably due to local mass effects that bring the patient to an early medical evaluation. Age distribution, sex
\end{abstract}

Correspondence to: Dr Alexandru Filipescu, Department of Obstetrics and Gynecology, 'Elias' Emergency University Hospital, 17 Mărăști Boulevard, 011461 Bucharest, Romania

E-mail: afilipescu@hotmail.com

Abbreviations: CT, computed tomography; cm, centimeter; g, grams; PHPT, primary hyperparathyroidism; PTH, parathyroid hormone or parathormone; PTA, parathyroid adenoma; GPTA, giant PTA; PC, parathyroid carcinoma

Key words: parathyroid adenoma, primary hyperparathyroidism, parathyroidectomy, calcium, vitamin D, parathyroid tumor, parathormone, giant parathyroid adenoma, incidentaloma, cyst ratio, rate of successful pre-operatory location do not differ from non-giant PTA. Hypovitaminosis D is more frequent in PTA of higher dimensions. Post-operative hypocalcemia, but not recurrent/persistent PHPT, is expected, even hungry bone disease. A higher rate of atypia is described although the tumor is mostly benign. Unusual presentations such as cystic transformation, initial diagnosis during pregnancy or auto-infarction have been reported. The ectopic localization of PTA presented in almost $15 \%$ of all cases may also be found in GPTA. What are the exact cutoffs for defining GPTA is still an open issue.

\section{Contents}

\section{Introduction}

2. Aim

3. Giant parathyroid adenoma: Concept around the size considerations

4. Pre-operative biological correlates

5. Relationship with vitamin D status

6. Histological issues

7. Ectopic PTA of large dimensions

8. Risk of post-operative hypocalcemia

9. Future considerations

10. Conclusions

\section{Introduction}

Primary hyperparathyroidism (PHPT), an endocrine condition caused by a parathyroid adenoma (PTA) (80-85\%), hyperplasia or carcinoma, has shifted in the modern era to a mildly symptomatic phenotype due to the 
prompt recognition of hypercalcemia and to a minimally invasive surgical approach which has a curative potential $(1,2)$. An overlap with a vitamin D deficiency-related secondary component is also common due to the global prevalence of hypovitaminosis D (1-3). The incidence of PHPT of 27 to 30 per 100,000 person-years increases with age and is 2 to 3 times higher in women $(4,5)$. In addition, a potential association of increased incidence and obesity has been described, but this condition has also experienced an increased general prevalence worldwide in addition to other multiple complications, whether they are bone-related or not $(6,7)$.

The clinical complications of PHTH are either related to high calcium levels (acute or chronic) or increased parathyroid hormone [also parathormone $(\mathrm{PTH})]$ or both such as osteoporosis and associated low-trauma fractures, neuropsychiatric disorders, neuromuscular manifestations, gastrointestinal disturbances, nephrocalcinosis, and urolithiasis, eventually complicated with urinary infections and kidney failure (8). When it comes to the primary tumor itself, typically the lesion is small and there are no local mass effects unless a carcinoma is the underling diagnosis which is positive in less than $1 \%$ of all cases, and also some exceptional cases of very large/giant parathyroid adenoma (GPTA) have been described (9). GPTA is an extremely rare type generally defined as having a weight of at least 3.5 grams ( $\mathrm{g}$ ) or $3 \mathrm{~g}$ (depending on the study), and some authors consider this particular endocrine mass as a distinct entity (9). Large PTA is usually considered a tumor weighing between 1 and $3 \mathrm{~g}$ (9). PTA, regardless of the size, are identified based on anterior cervical ultrasound, magnetic resonance imaging (MRI), and computed tomography (CT) as well as functional imagery such as ${ }^{99}$ Technetium-labelled sestamibi-single photon emission CT or scintigraphy $(1,9)$. Regardless of the dimension, surgical removal of a PTA cures the disease with a considerable improvement of many of the associated complications (unless severe kidney disease is already established) (10).

\section{Aim}

This article is a review of the literature regarding GPTA that causes PHPT focusing on different aspects including pre-operative biochemistry correlates, post-parathyroidectomy outcome, histological issues, unusual locations as ectopic/intra-thyroid, and particular clinical aspects such as diagnosis during pregnancy. The main research tool was the PubMed database. A number of 90 references are cited. We systematized in a table the papers published between 2010 and 2020 displaying HPTH-related GPTA. The level of evidence varied from case report or series to retrospective studies or meta-analyses. Cases with parathyroid carcinoma or hyperplasia or associated multiple endocrine neoplasia syndromes were not included.

\section{Giant parathyroid adenoma: Concept around the size considerations}

Spanheimer et al considered that a GPTA may represent a particular condition characterized by a larger lesion, a paradoxically less severe phenotype at presentation and a more severe evolution after surgical removal in terms of low calcium levels, not of persistent/recurrent hypercalcemia (9). This study included 300 patients that identified 15 GPTAs with a weight $>3.5 \mathrm{~g}$ or $\geq 95$ th percentile (median GPTA weight of $5.65 \mathrm{~g}$ ) vs. non-giant PTA group of 285 subjects (median PTA weight of $0.56 \mathrm{~g}$ ) (9). Analyzing the clinical and laboratory features, the patients with a giant lesion had a statistically significant higher value of calcium (11.07 vs. $10.9 \mathrm{mg} / \mathrm{dl})$ and PTH (227.6 vs. $136.7 \mathrm{pg} / \mathrm{ml}$ ) before surgery and a lower percent of symptomatic PHPT (9). The pre-operative success rate of localization using different imaging techniques was similar between the two groups (9). The risk of post-operative symptomatic hypocalcemia was higher in GPTA (9). The groups were similar regarding age at diagnosis, sex ratio, location, and the rate of post-operative persistent/recurrent hyperparathyroidism (9).

\section{Pre-operative biological correlates}

Leong et al published a retrospective study between 2013 and 2018 of 555 patients (a mean PTA weight of $1.022 \mathrm{~g}$ ) and found a strong positive correlation between preoperative PTH levels and parathyroid weight $(r=0.602, \mathrm{P}<0.001)$, a medium correlation between calcium before surgery and parathyroid gland $(\mathrm{r}=0.474, \mathrm{P}<0.001)$. Thus, $\mathrm{PTH}$ appears to be a better predictor of PTA weight than calcemic levels (11). Another cohort of 378 cases presenting with PHPT found a statistically significant correlation of preoperative calcium, respective PTH values and adenoma dimensions and weight. A calcium level $>11.5 \mathrm{mg} / \mathrm{dl}$ and PTH $>165 \mathrm{pg} / \mathrm{ml}$ were found to predict a PTA of more than $2.18 \mathrm{~cm}$ and $2.7 \mathrm{~g} \mathrm{(12).}$ A statistically significant correlation $(\mathrm{P}=0.0001)$ between adenoma weight with serum calcium, respective PTH (and not serum phosphate) was pointed out in a retrospective study of 69 cases with a mean age of 54 years (mean PTH of PTA of $770.971 \mathrm{pg} / \mathrm{ml}$ before surgical removal in association with mean total calcium of $11.47 \mathrm{mg} / \mathrm{dl}$ ) (13). A study in 2019 of 519 candidates for parathyroidectomy considered 'dwarf' PTA the cases with a tumor weight of $<3 \mathrm{~g}(\mathrm{~N}=100$, median $2 \mathrm{~g})$ vs. 'giant' PTA, tumors more than $3 \mathrm{~g}(\mathrm{~N}=56$, median weight of $4.3 \mathrm{~g}$ ) (14). 'Dwarf' when compared with GPTA had statistically significant lower values of calcium and PTH, but overall a weak correlation of biochemistry parameters to adenoma size was established (14). During 40 months of post-operative follow-up, none of the GPTA cases had recurrent disease; the fact that the tumor was large did not underline a malignancy (14). Grover et al published a study in 2020 of 79 patients with PHPT and PTA; $11.3 \%$ of them had a giant tumor (maximum diameter between 3.5 and $5.5 \mathrm{~cm}$ ) without pre-operative correlations in biochemical elements and adenoma size (15). Another potential useful correlation was described in one study between neutrophil/lymphocyte ratio and PTA size (a study on 32 parathyroid tumors, mean age of 53 years, $75 \%$ of them were females) (16).

\section{Relationship with vitamin D status}

Vitamin D deficiency is a stimulus for parathyroid hyperplasia; the component of secondary hyperparathyroidism may be 
additional to a primary one and it may cause a supplementary increase in parathyroid tumor, regardless of the positive diagnosis of associated osteoporosis, menopausal status or body weight (17). Agarwal et al studied the influence of vitamin D levels and parathyroid tumor weight on 59 patients that were included in a retrospective case-control study based on the PTA weight as small $<1 \mathrm{~g}$ ( $\mathrm{N}=12$ patients), large PTA of 1-3 $\mathrm{g}$ ( $\mathrm{N}=34$ subjects), GPTA of $>3 \mathrm{~g}(\mathrm{~N}=13$ patients) and based on the 25-hydroxyvitamin D level (deficient, insufficient, sufficient). PTH was higher in vitamin D deficient vs. sufficient subjects while 25-hydroxyvitamin D was lower in patients with larger vs. smaller tumors (18). A prospective study on 51 consecutive patients (mean age of 43 years) with PTA also grouped the PTA based on weight: small $<1 \mathrm{~g}$, large 1-3 g, GPTA $>3 \mathrm{~g}$ and it showed a higher percentage of hypovitaminosis D in GPTA (19).

\section{Histological issues}

Authors have questioned whether GPTAs have a higher risk of malignancy (20). A retrospective analysis of 3,643 PTAs included 52 atypical PTA $(\mathrm{N}=34)$ and 18 malignant parathyroid carcinoma (PC) concluded that PCs have statistically significant higher dimensions (20). Another retrospective analysis of 353 PTA patients divided the lesions into small and large tumor weight (a cut-off of $2 \mathrm{~g}$ ) and found a statistically significantly higher frequency of atypical lesions among the large tumors (21). Chandramohan et al published a retrospective analysis of 264 patients with PHPT, and 26 patients of these exhibited atypical ultrasound features associated with a larger lesion of the adenoma (22). In 2020, an exceptional case presenting with a GPTA mimicking PC was published. The histological report showed a tumor with dimensions $6.5 \times 5 \times 3 \mathrm{~cm}$; weight of $90 \mathrm{~g}$ with preoperative hypercalcemia of $12.5 \mathrm{mg} / \mathrm{dl}$ and PTH of $2,747 \mathrm{pg} / \mathrm{ml}$, noting that in the literature the largest weight was $145 \mathrm{~g}$ in a female with a GPTA $(23,24)$.

Another unexpected situation is the process of apoplexy in GPTA (25). Garrahy et al reported a case of a 45-year-old female with acute airway compromise due to PTA apoplexy with a mass effect (hypercalcemia of $13.3 \mathrm{mg} / \mathrm{dl}$, and PTH of $367 \mathrm{pg} / \mathrm{ml}$ ) due to a PTA of $10.7 \times 5.2 \times 4.2 \mathrm{~cm}(25)$.

Cystic GPTA associated or not with PHPH have been reported, and liquid accumulation is expected to increase the tumor size (26-28). The parathyroid cysts, functional or non-functional, represent less than $1 \%$ of all neck cysts of different etiologies (26-28). Here a few studies are presented. Pontikides et al published 9 cases of cystic parathyroid lesions (female/male ratio of 7/2), of nonfunctioning type (6/9) and with HPTH (3/9) (27). Ghasemi-Rad et al published a retrospective study of 109 cystic (26/109, mean age 43.3 years) and solid (83/109, mean age 48.6 years) adenomas associated with a serum calcium level statistically significant higher in the solid PTA group (11.18 vs. $11.95 \mathrm{mg} / \mathrm{dl})$ while size was higher in the cystic group (28). Hu et al published a retrospective study of 907 patients. The cystic PTAs (37/907) when compared with the solid PTAs (870/907) showed higher PTH, calcium values, and increased risk of hypercalcemic crisis (29). Papavramidis et al published a meta-analysis of cases with 359 cystic PTAs of mean age 49.24 years (females/males: 65/35\%), either asymptomatic or running as $\mathrm{HPTH}$, of mean $4.81 \mathrm{~cm}$ (ranging from 0.5 to $15 \mathrm{~cm}$ ) (30).

\section{Ectopic PTA of large dimensions}

Ectopic PTA tissue is not uncommon, with an incidence of approximately $16 \%$ of all cases according to one study from 2019, and some of them are GPTA without a clear incidence (31). The most common sites are the mediastinum, thymus and thyroid (31). A previously mentioned case that was published in 2011, introduces a female with giant mediastinal PTA measuring 7x5x4 cm and weighing $145 \mathrm{~g}$ (PTH of $642 \mathrm{pg} / \mathrm{ml}$ and calcium of $13.2 \mathrm{mg} / \mathrm{dl}$ ) (24). Intra-thyroid PTA of large dimensions have been reported $(32,33)$. For instance, Yalcin et al published such a case of a 76-year-old female with preoperative biochemistry revealing hypercalcemia $(12 \mathrm{mg} / \mathrm{dl})$ with high levels of parathyroid hormone $(512 \mathrm{pg} / \mathrm{ml})$, and a lesion of 2.4x1.9x1.6 cm (33). Vilallonga et al reported a giant inthra-thyroidal parathyroid adenoma of $3 \mathrm{~cm}$ maximum diameter, weighing $70 \mathrm{~g}$ in a 19-year-old patient with hypercalcemia (14.2 mg/dl) and elevated PTH (1207 pg/ml) (34). Silaghi et al reported an intra-thyroid PTA of $4 \mathrm{~cm}$, complicated with brown tumors (35). Another case with high dimensions at ultrasound was that of a 82-year-old male who presented with classical PHPT symptoms, increased calcium levels and high PTH of $210.4 \mathrm{pg} / \mathrm{ml}$, with a thyroid ultrasound revealing a giant intra-thyroidal nodule (a PTA) of $6.9 \times 5.2 \times 4.8 \mathrm{~cm} \mathrm{(36)}$

\section{Risk of post-operative hypocalcemia}

Most authors agree that after removal of a GPTA, the risk of developing low PTH-related hypocalcemia is higher than seen in patients with smaller tumors $(37,38)$. Hungry bone syndrome may be expected especially if pre-operative PTH is highly increased (37,38). A cases series of 3 GPTAs exhibited severe hypocalcemia after surgery: a 57-year old male with PTH of $1,780 \mathrm{pg} / \mathrm{ml}$, calcium of $14.14 \mathrm{mg} / \mathrm{dl}$, ultrasound features of the PTA of 5x3x2 cm, a weight of $30.6 \mathrm{~g}$; a 60 -year old female, with calcium of $16.17 \mathrm{mg} / \mathrm{dl}$, PTH of $863 \mathrm{pg} / \mathrm{ml}$, tumor dimension $5.5 \times 4 \times 3 \mathrm{~cm}$, a weight of $35.2 \mathrm{~g}$, and also a 33 -year old subject with calcium of $12.58 \mathrm{mg} / \mathrm{dl}$, PTH of $1,174 \mathrm{pg} / \mathrm{ml}$, and $30 \mathrm{~g}$ weight for the PTA (39).

Another exceptional condition is hypocalcemia following an auto-infarction of a previously known or unknown PTA (40). For instance, a reported case from 2018 revealed such a situation involving a GPTA auto-infarction resulting in hungry bone syndrome (40). This case was a 71-year-old man known with atrial fibrillation, treated with rivaroxaban, who was found with severe hypercalcemia of $14.6 \mathrm{mg} / \mathrm{dl}$ and elevated PTH of 2,555 pg/ml; ultrasound size of PTA was $4.1 \times 3.6 \times 3.1 \mathrm{~cm}$ (40). Therefore, a parathyroidectomy was planned, rivaroxaban was halted 5 days prior to surgery, but the patient developed hypocalcemia before surgery due to spontaneous infarct of the tumor (40). Whether the use of an anticoagulant is a trigger for self-infarction as seen in adrenal glands, it is difficult to establish due to the limited published data (40). Novodvorsky et al reported a series of two cases with auto-infarction: a 51-year-old subject with hypercalcemia of $12.44 \mathrm{mg} / \mathrm{dl}$, PTH of $253.66 \mathrm{pg} / \mathrm{ml}$, PTA at ultrasound of 


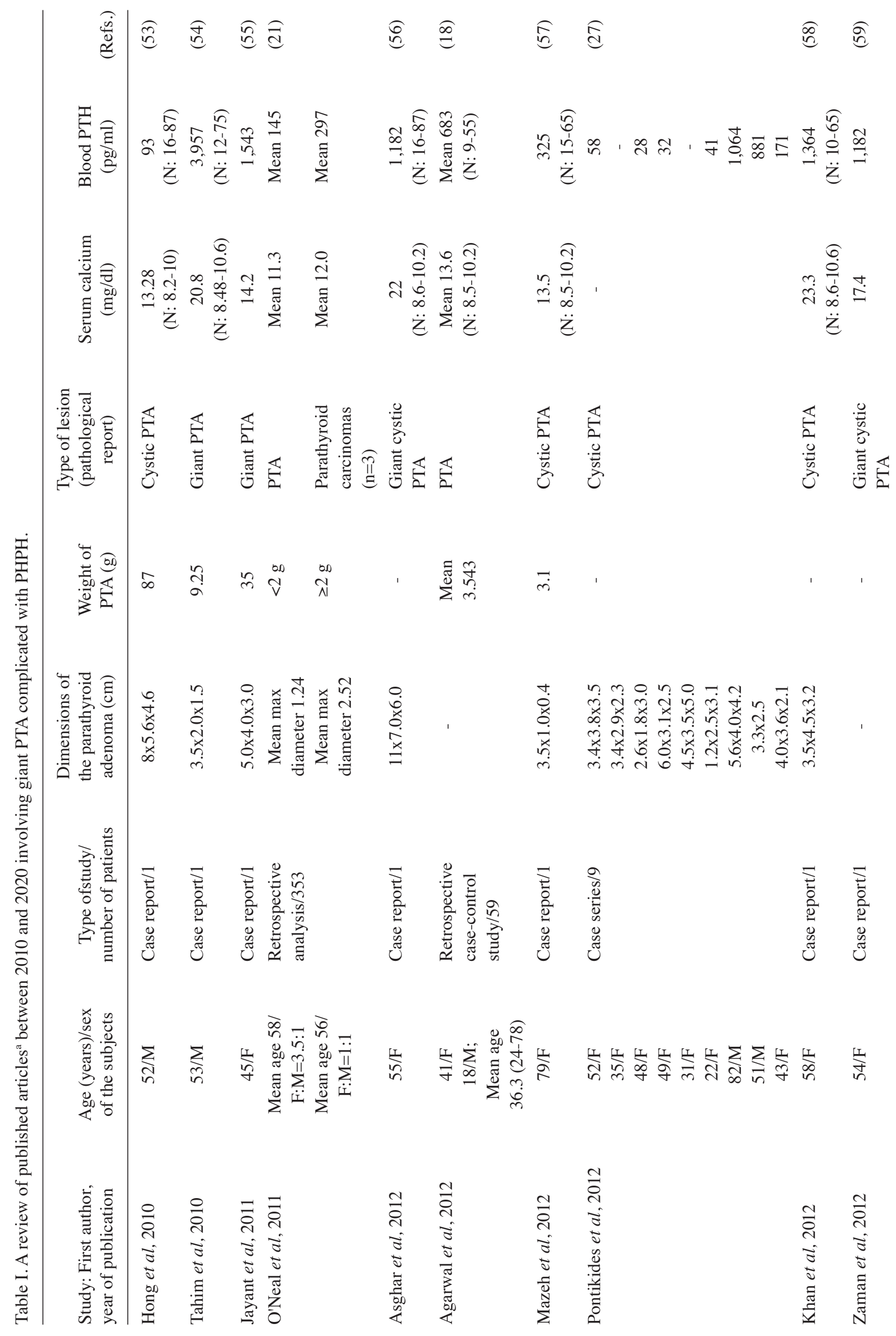




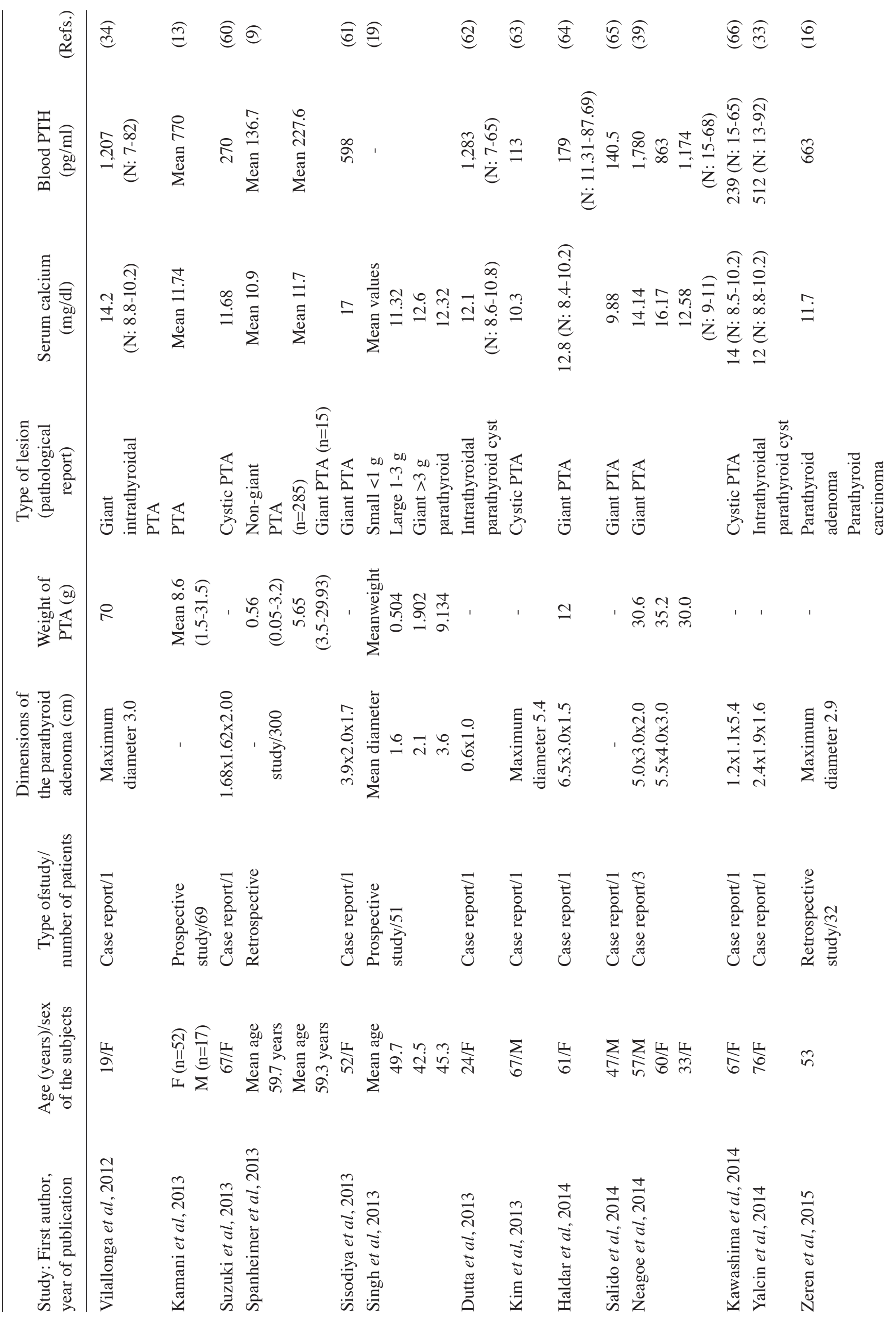




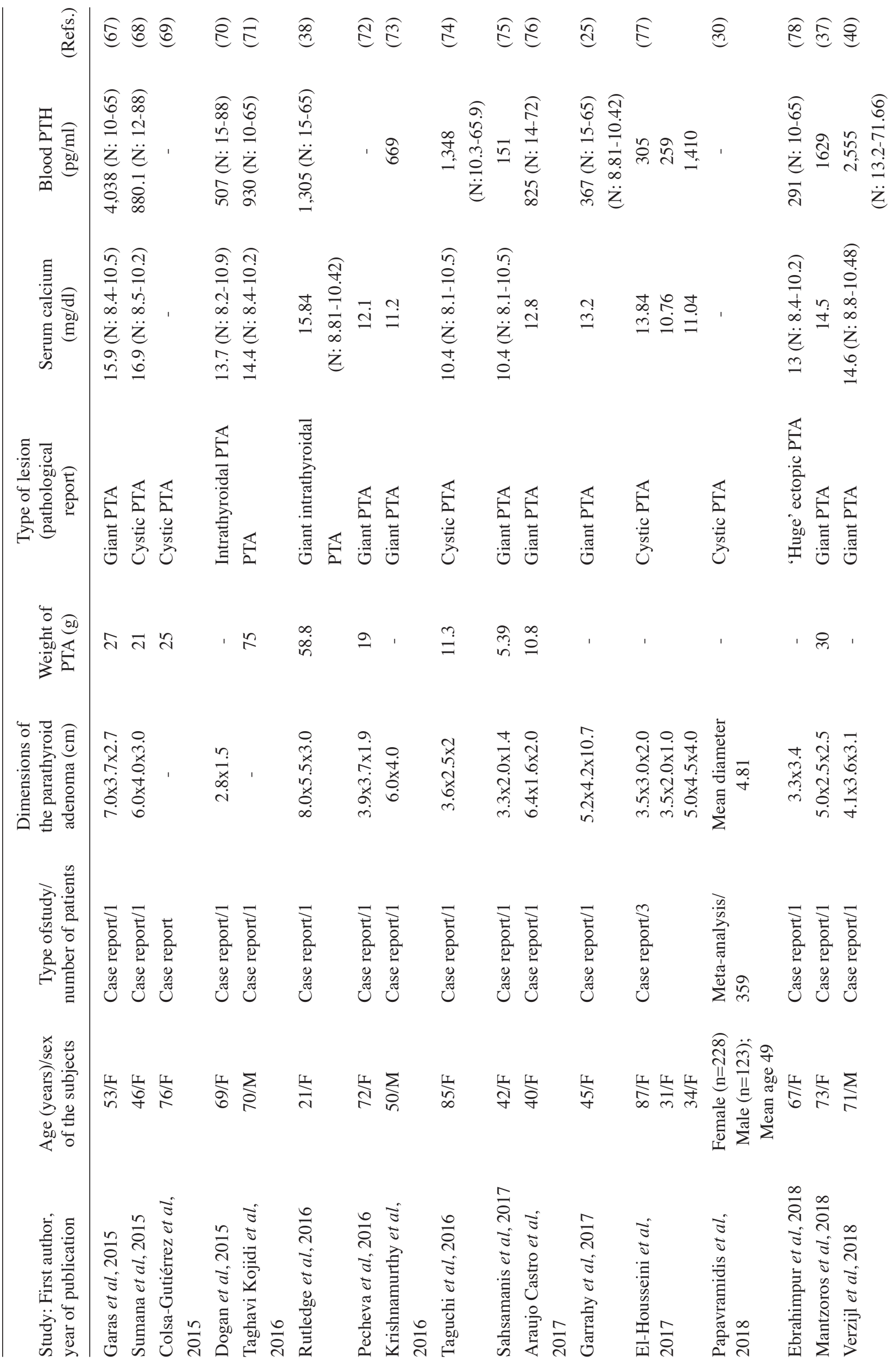




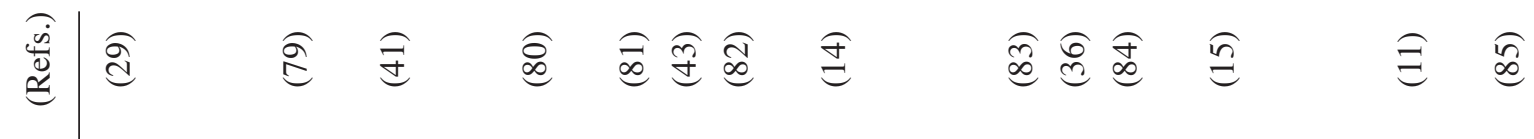

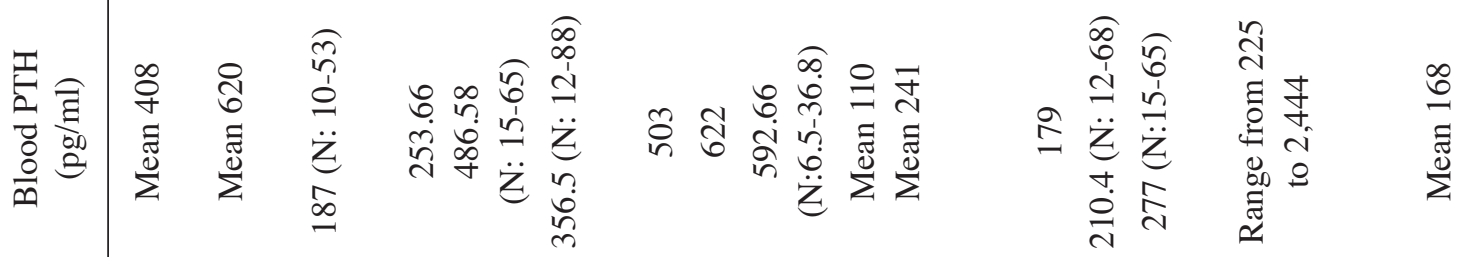

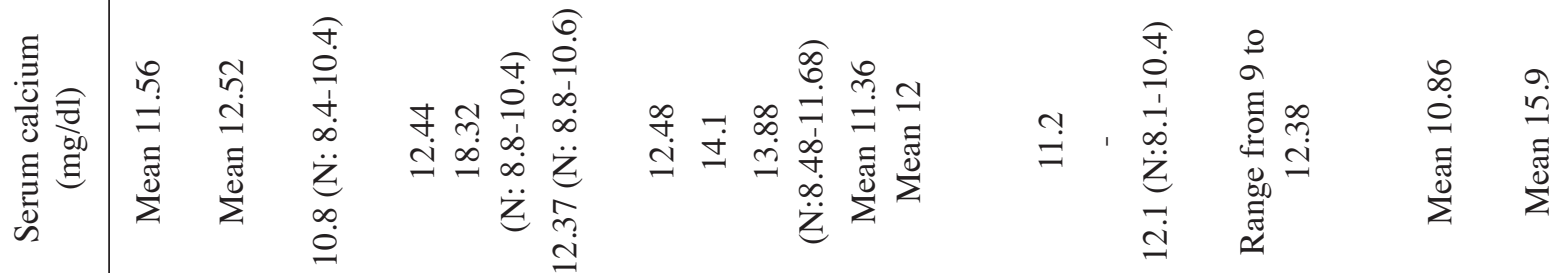

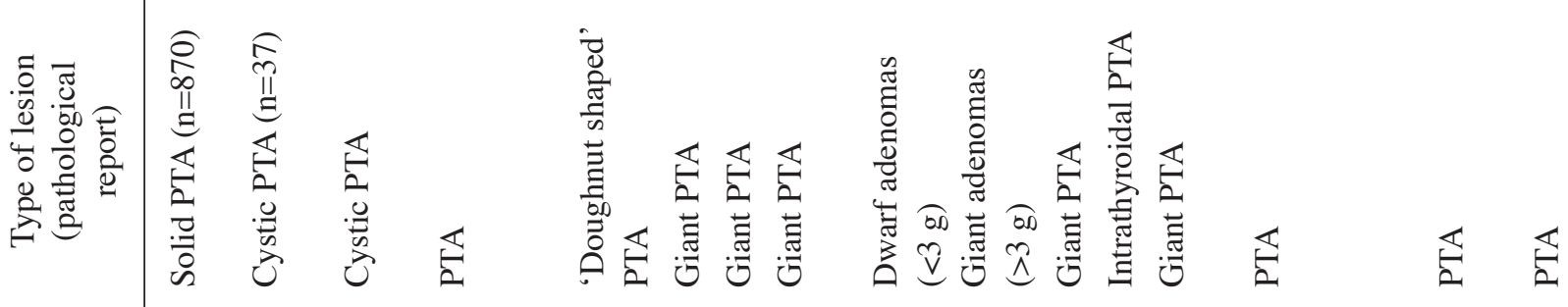

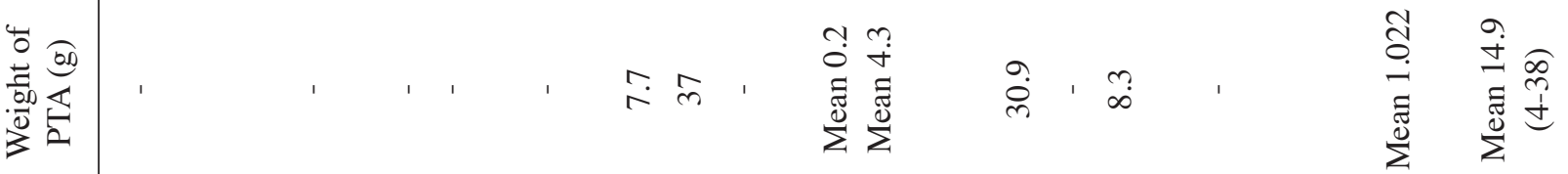

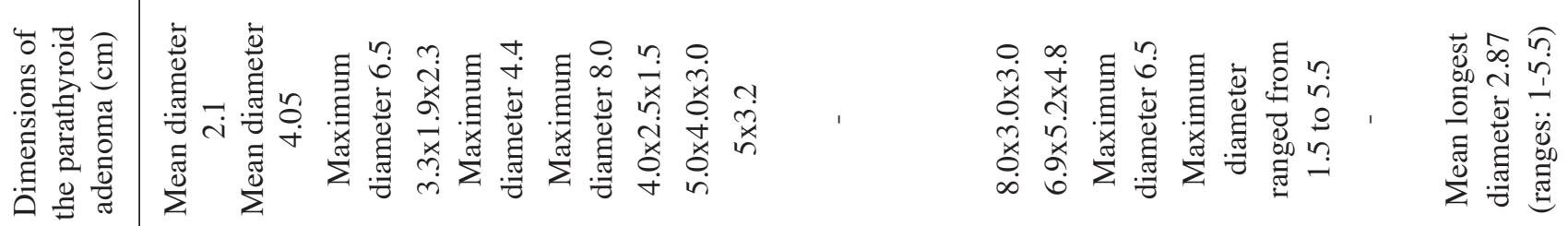

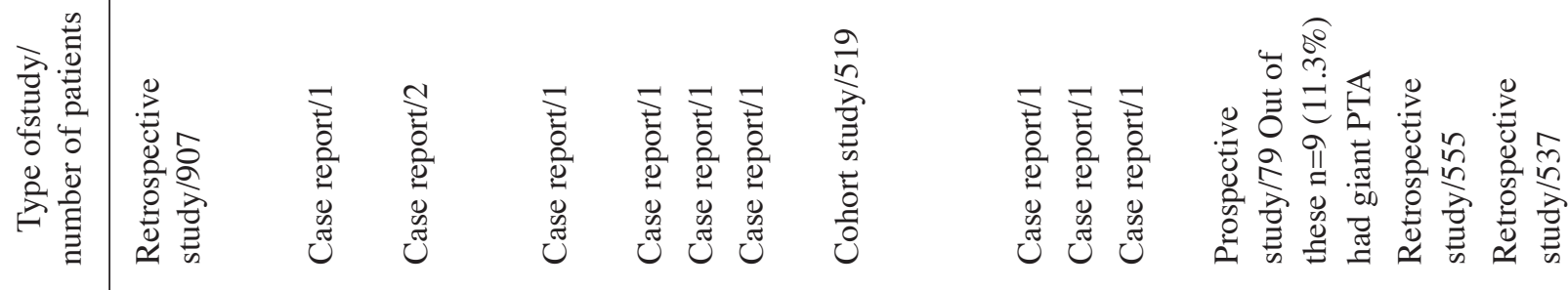

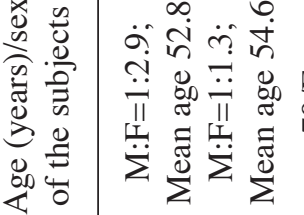

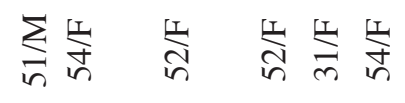 ๘ี 
$3.3 \times 1.9 \times 2.3 \mathrm{~cm}$ and a 54-year-old patient admitted for severe hypercalcemia of $18.32 \mathrm{mg} / \mathrm{dl}$ in addition to increased PTH of $486.58 \mathrm{pg} / \mathrm{ml}$ associated with a PTA of $4.4 \mathrm{~cm}$ at MRI (41). The two cases with auto-infarction were managed differently, the first case underwent surgery and the second case was conservatively approached (41).

Table I introduces the review of the literature of cases/studies identified between 2010 and 2020 available via PubMed in the field of HPTH-related GPTA.

\section{Future considerations}

Several topics are still an open issue since, to date, only a limited amount of published data are available. We mention three such categories.

Diagnosis of GPTA during pregnancy. PHTP is exceptionally diagnosed during pregnancy starting most probably from the detection of high calcium values which might be completely asymptomatic $(42,43)$. The newborn may experience convulsions after birth due to calcium metabolism anomalies (42). Some single case reports introduce such situations such as a 29-year-old pregnant female with double PTAs causing PHTP (a calcium level of $11.3 \mathrm{mg} / \mathrm{dl}$, and a PTH of $678 \mathrm{pg} / \mathrm{ml}$ ) or a diagnosis of HPTP during the first trimester of pregnancy in a female with a serum calcium of $14.1 \mathrm{mg} / \mathrm{dl}$ due to high PTH of $622 \mathrm{pg} / \mathrm{ml}$ underling a GPTA of $5 \times 4 \times 3 \mathrm{~cm}$ with a weight of $37 \mathrm{~g}(42,43)$.

Syndromic PHTP-related parathyroid tumors. PHTP is associated with a multitude of other non-parathyroid endocrine/neuroendocrine and non-endocrine tumors such as type IIA multiple endocrine neoplasia; but in cases with specific gene background as RET mutations, the parathyroid tumors actually underline a hyperplasia, not an adenoma (44-48). Since the relationship with genetic makeup and the presence of other tumors influence the timing of PHTP diagnosis and its frequency among a particular syndrome such as other less described neoplasia associations are still incompletely understood (for instance, meningioma and PTA), we consider this heterogeneous chapter a completely different topic and thus we did not discuss it here $(47,48)$.

Parathyroid incidentaloma. The detection of a parathyroid tumor, even very large (especially it is posterior cervical or ectopic), may be incidental, and the assessment of the biochemistry and endocrine panel may become irrelevant, meaning that PHPT is not confirmed (49,50). The diagnosis of PHPT is based exclusively on biological data, a synchronous increase in both calcium and PTH, at least two assays; thus imaging findings, even impressive like in cases of large/giant PTA, do not impact the diagnosis of PHPT itself $(1,49,50)$. Surgical removal of a non-functioning PTA depends mostly on the size and local compressive effects $(1,49,50)$. However, when it comes to a GPTA respecting an incidentaloma scenario, the tumor may be non-functional, but in most cases the clinical identification comes first because of the neoplasia size, thus the accidental imaging detection as part of traditional endocrine incidentaloma definition is not applicable (49). Incidentalomas at the level of the parathyroid gland, regardless of the size, are 
still a controversy issue in relationship to a clear definition, standards or protocol of management and follow-up, contrary to the massive amount of medical information we have up to this moment about adrenal and pituitary incidentaloma, regardless of whether they are cystic or solid or mixed, of small or large dimensions $(49,50)$. We report here two cases of giant non-functioning PTA. Mossinelli et al described a case of a 46-year-old male with a giant retro-tracheal non-functioning PTA (measuring $5.5 \times 4 \times 2.5 \mathrm{~cm}$ and weighing $42 \mathrm{~g}$; normal calcium levels of $9.2 \mathrm{mg} / \mathrm{dl}$ and PTH of $70.03 \mathrm{pg} / \mathrm{ml})(51)$ Zhang et al described a 56-year-old male with a compressive giant non-functional parathyroid cyst of 9x6 cm associated with a serum calcium value of $9 \mathrm{mg} / \mathrm{dl}$, and a PTH level of $37.98 \mathrm{pg} / \mathrm{ml}$ (52).

Table I introduces the review of the literature of cases/studies identified between 2010 and 2020 available via PubMed in the field of HPTH-related GPTA (11,13-16,18,19,21,23,25,27,29,30,32-34,36-41,43,53-90).

\section{Conclusions}

A GPTA represents a fascinating particular entity that is associated, in most cases, with PHPT with higher calcium/PTH values at detection, but less complications of PHPT vs. non-giant PTA, probably due to the local mass effects that bring the patient to an early medical evaluation. Post-operative hypocalcemia, but not necessarily recurrent/persistent PHPT, is expected, and even hungry bone disease. A higher rate of atypia is described although the tumor is mostly benign. Unusual presentations such as cystic transformation or diagnosis during pregnancy have been reported. An ectopic PTA localization of almost $15 \%$ of cases may also be found. The cut-off for defining a GPTA is still an open issue; but, the values used so far, include a weight of $>3-3.5 \mathrm{~g}$.

\section{Acknowledgements}

Not applicable.

\section{Funding}

No funding was received.

\section{Availability of data and materials}

All information is documented by relevant references.

\section{Authors' contributions}

AG drafted the manuscript and critically revised the final form. AIT drafted the manuscript in light of the literature studies. EP researched the literature data. MC drafted the manuscript in light of the literature studies. AV researched the literature. AF is the corresponding author and helped the manuscript drafting in light of the literature studies. AMO researched the literature in connection with all cases of giant parathyroid adenoma and wrote the article according to the requirements of the journal. FS drafted the manuscript, revised the English language of the article and researched the literature with the selection of all the data necessary for the writing of the article. All authors read and approved the final manuscript for publication.

\section{Ethics approval and consent to participate}

Not applicable.

\section{Patient consent for publication}

Not applicable.

\section{Competing interests}

The authors declare that they have no competing interests.

\section{References}

1. Yadav SK, Johri G, Bichoo RA, Jha CK, Kintu-Luwaga R and Mishra SK: Primary hyperparathyroidism in developing world: A systematic review on the changing clinical profile of the disease. Arch Endocrinol Metab 64: 105-110, 2020.

2. Madkhali T, Alhefdhi A, Chen H and Elfenbein D: Primary hyperparathyroidism. Ulus Cerrahi Derg 32: 58-66, 2016.

3. Păduraru DN, Moldovan C, Morar A, Bolocan A, Botezan O, Andronic O, Ene A, Socea B, Turturea R, Carsote M, et al: Complications before surgery: Primary hyperparathyroidism. Rom J Clin Res 2: 86-90, 2019.

4. Fraser WD: Hyperparathyroidism. Lancet 374: 145-158, 2009.

5. Wilhelm SM, Wang TS, Ruan DT, Lee JA, Asa SL, Duh QY, Doherty GM, Herrera MF, Pasieka JL, Perrier ND, et al: The American association of endocrine surgeons guidelines for definitive management of primary hyperparathyroidism. JAMA Surg 151: 959-968, 2016.

6. Dumitrascu MC, Stanescu AMA, Bejan C, Sandru F, Toader DO, Radavoi DG, Cotirlet A, Judea Pusta CT and Diaconu CC: Obesity and its implications on stress urinary incontinence. Rev Chim 70: 3660-1662, 2019.

7. Sandru F, Dumitrascu MC, Albu SE, Carsote M and Valea A: Obesity and osteoporotic fractures. Rom J Mil Med 123: 166-171, 2020.

8. Hindié E, Ugur O, Fuster D, O'Doherty M, Grassetto G, Ureña P, Kettle A, Gulec SA, Pons F and Rubello D; Parathyroid Task Group of the EANM: 2009 EANM parathyroid guidelines. Eur J Nucl Med Mol Imaging 36: 1201-1216, 2009.

9. Spanheimer PM, Stoltze AJ, Howe JR, Sugg SL, Lal G and Weigel RJ: Do giant parathyroid adenomas represent a distinct clinical entity? Surgery 154: 714-719, 2013.

10. Carsote M, Paduraru DN, Nica AE and Valea A: Parathyroidectomy: Is vitamin D a player for a good outcome? J Med Life 9: 348-352, 2016.

11. Leong DCW, Lo J, Nguyen H and Ryan S: Can we predict expected adenoma weight preoperatively with reference to the correlation of preoperative biochemical tests with parathyroid adenoma weight? Asian J Surg 43: 759-764, 2020.

12. Stern S, Mizrachi A, Strenov Y, Knaanie A, Benbassat C, Shpitzer T and Bachar G: Parathyroid adenoma: A comprehensive biochemical and histological correlative study. Clin Otolaryngol 42: 381-386, 2017.

13. Kamani F, Najafi A, Mohammadi SS, Tavassoli S and Shojaei SP: Correlation of biochemical markers of primary hyperparathyroidism with single adenoma weight and volume. Indian J Surg 75: 102-105, 2013.

14. Abdel-Aziz TE, Gleeson F, Sadler G and Mihai R: Dwarfs and giants of parathyroid adenomas-no difference in outcome after parathyroidectomy. J Surg Res 237: 56-60, 2019.

15. Grover M, Sharma M, Bhandari S, Sharma B, Bhargva S and Samdhani S: Giant parathyroid adenoma: Are they different? Indian J Otolaryngol Head Neck Surg: 1-4, 2020

16. Zeren S, Yaylak F, Ozbay I and Bayhan Z: Relationship between the neutrophil to lymphocyte ratio and parathyroid adenoma size in patients with primary hyperparathyroidism. Int Surg 100: 1185-1189, 2015. 
17. Ghemigian A, Radu O, Valea A, Dumitru N, Buruiana A and Carsote M: Hypovitaminosis D and Menopause: Still an issue in 2016? Rom Med J 63: 209-210, 2016.

18. Agarwal G, Sadacharan D, Ramakant P, Shukla M and Mishra SK: The impact of vitamin D status and tumor size on the intraoperative parathyroid hormone dynamics in patients with symptomatic primary hyperparathyroidism. Surg Today 42 : 1183-1188, 2012

19. Singh DN, Gupta SK, Chand G, Mishra A, Agarwal G, Verma AK, Mishra SK, Shukla M and Agarwal A: Intra-operative parathyroid hormone kinetics and influencing factors with high baseline PTH: A prospective study. Clin Endocrinol (Oxf) 78: 935-941, 2013.

20. Quinn CE, Healy J, Lebastchi AH, Brown TC, Stein JE, Prasad ML, Callender GG, Carling T and Udelsman R: Modern experience with aggressive parathyroid tumors in a high-volume new england referral center. J Am Coll Surg 220: 1054-1062, 2015.

21. O'Neal P, Mowschenson P, Connolly J and Hasselgren PO: Large parathyroid tumors have an increased risk of atypia and carcinoma. Am J Surg 202: 146-150, 2011.

22. Chandramohan A, Sathyakumar K, John RA, Manipadam MT, Abraham D, Paul TV, Thomas N and Paul MJ: Atypical ultrasound features of parathyroid tumours may bear a relationship to their clinical and biochemical presentation. Insights Imaging 5: 103-111, 2014.

23. Evola G, Tavarelli M, Evola FR, Sapuppo G, Pellegriti G and Masucci R: Giant parathyroid adenoma: A rare cause of primary hyperparathyroidism mimicking a carcinoma. Endokrynol Pol 71: 359-360, 2020

24. Cakmak H, Tokat AO, Karasu S and Özkan M: Dev mediastinal paratiroid adenoma. Tuberk Toraks 59: 263-265, 2011.

25. Garrahy A, Hogan D, O'Neill JP and Agha A: Acute airway compromise due to parathyroid tumour apoplexy: An exceptionally rare and potentially life-threatening presentation. BMC Endocr Disord 17: 35, 2017.

26. Arduc A, Tutuncu YA, Dogan BA, Arikan Ileri AB, Tuna MM Ozcan HN, Isik S, Berker D and Guler S: Parathyroid cysts. Am Surg 81: E163-E165, 2015.

27. Pontikides N, Karras S, Kaprara A, Cheva A, Botsios D, Moschidis A, Efthimiou E, Wass J and Krassas G: Diagnostic and therapeutic review of cystic parathyroid lesions. Hormones (Athens) 11: 410-418, 2012.

28. Ghasemi-Rad M Lesha E, Abkhiz S and Mohammadi A: Primary hyperparathyroidism: Comparing between solid and cystic adenomas and the efficacy of ultrasound and single-photon emission computed tomography in their diagnosis. Endocr Pract 21: $1277-1281,2015$.

29. Hu Y, Cui M, Xia Y, Su Z, Zhang X, Liao Q, Jiang Y and Zhao Y: The clinical features of cystic parathyroid adenoma in Chinese population: A single-center experience. Int J Endocrinol 2018: 3745239, 2018

30. Papavramidis TS, Chorti A, Pliakos I, Panidis S and Michalopoulos A: Parathyroid cysts: A review of 359 patients reported in the international literature. Medicine (Baltimore) 97: e11399, 2018.

31. Taterra D, Wong LM, Vikse J, Sanna B, Pękala P, Walocha J, Cirocchi R, Tomaszewski K and Henry BM: The prevalence and anatomy of parathyroid glands: A meta-analysis with implications for parathyroid surgery. Langenbecks Arch Surg 404: 63-70, 2019.

32. Papanikolaou A, Katsamakas M, Boudina M, Pamporaki C, Intzidis I, Kiziridou A, Kleidaradaki E, Rakitzi P, Venetsanaki V and Chrisoulidou A: Intrathyroidal parathyroid adenoma mimicking thyroid cancer. Endocr J 67: 639-6343, 2020.

33. Yalcin Y, Mete T, Aktimur R, Kucuk GO, Duman G, Ozbalci AB and Alici O: A case of primary hyperparathyroidism due to intrathyroidal parathyroid cyst. Case Rep Endocrinol 2014: 213283, 2014.

34. Vilallonga R, Zafón C, Migone R and Baena JA: Giant intrathyroidal parathyroid adenoma. J Emerg Trauma Shock 5: 196-198, 2012.

35. Silaghi H, Valea A, Ghervan C and Silaghi AC: Ectopic intrathyroid parathyroid adenoma: Diagnostic and therapeutic challenges due to multiple osteolytic lesions. Case report. Med Ultrason 13: 241-244, 2011

36. Chen J, Ma Z and Yu J: Diagnostic pitfalls in a cystic ectopic intrathyroidal parathyroid adenoma mimicking a nodular goiter: A care-compliant case report. Medicine (Baltimore) 98: e14351, 2019.
37. Mantzoros I, Kyriakidou D, Galanos-Demiris K, Chatzakis C, Parpoudi S, Sapidis N, Loutzidou L, Ioannidis O, Angelopoulos S and Tsalis KG: A rare case of primary hyperparathyroidism caused by a giant solitary parathyroid adenoma. Am J Case Rep 19: 1334-1337, 2018.

38. Rutledge S, Harrison M, O'Connell M, O'Dwyer T and Byrne MM: Acute presentation of a giant intrathyroidal parathyroid adenoma: A case report. J Med Case Rep 10: 286, 2016.

39. Neagoe RM, Sala DT, Borda A, Mogoantǎ CA and Múhlfay G: Clinicopathologic and therapeutic aspects of giant parathyroid adenomas-three case reports and short review of the literature. Rom J Morphol Embryol 55 (Suppl): S669-S674, 2014.

40. Verzijl R, Bongers PJ, Mukerji G, Mete O, Devon KM and Pasternak JD: Autoinfarction of giant parathyroid adenoma after preoperative withdrawal of anticoagulants. Case Rep Surg 2018: 9261749,2018

41. Novodvorsky P, Hussein Z, Arshad MF, Iqbal A, Fernando M, Munir A and Balasubramanian SP: Two cases of spontaneous remission of primary hyperparathyroidism due to auto-infarction: Different management and their outcomes. Endocrinol Diabetes Metab Case Rep 2019: 18-0136, 2019 (Epub ahead of print).

42. Zachariah SK and Thomas PA: Primary hyperparathyroidism: A report of two unusual cases. Indian J Surg 72: 135-137, 2010.

43. Mirza R and Wei EX: A giant parathyroid tumor during pregnancy: Adenoma versus carcinoma. Case Rep Pathol 2019: 4383698, 2019.

44. Sandru F, Carsote M, Albu SE, Valea A, Petca A and Dumitrascu MC: Glucagonoma: From skin lesions to the neuroendocrine component (Review). ExpTher Med 20: 3389-3393, 2020.

45. Sandru F, Carsote M, Valea A, Albu SE, Petca RC and Dumitrascu MC: Somatostatinoma: Beyond neurofibromatosis type 1 (Review). Exp Ther Med 20: 3383-3388, 2020.

46. Iliesiu A, Ungureanu IA, Petca A, Constantin MM, Petca RC, Sandru F, Constantin T and Dumitrascu MC: Paraganglioma presenting as a mesenteric cystic mass: A case report. Exp Ther Med 20: 2489-2492, 2020.

47. Miulescu R, Balaban DV, Sandru F and Jinga M: Cutaneous manifestations in pancreatic diseases-a review. J Clin Med 9: 2611,2020

48. Valea A, Radu O, Morar A, Ghemigian A and Carsote M: Synchronous medullar thyroid cancer and primary hyperparathyroidism on a female within the sixth decade of life with positive family history for type 2 A MEN syndrome. J Med Pract 4: 11: 346-349, 2016.

49. Poiana C, Carsote M, Chirita C, Terzea D, Paun S and Beuran M: Giant adrenal cyst: Case study. J Med Life 3: 308-313, 2010.

50. Poiană C, Chiriță C, Carşote M, Hortopan D, Ioachim D, Corneci CM and Stănescu B: Adrenal and pituitary incidentalomas in a case of Cushing's syndrome. Chirurgia (Bucur) 108: 886-891, 2013.

51. Mossinelli C, Saibene AM, De Pasquale L and Maccari A Challenging neck mass: Non-functional giant parathyroid adenoma. BMJ Case Rep 2016: bcr2016215973, 2016.

52. Zhang X, Yuan JH, Feng L, Shan DQ, Wu JF and Liu ST: Giant non-functional parathyroid cyst: A case report. Oncol Lett 11: 2237-2240, 2016

53. Hong JJ, Schrump DS and Hughes MS: Image of the month. Cystic parathyroid adenoma. Arch Surg 145: 705, 2010.

54. Tahim AS, Saunders J and Sinha P: A parathyroid adenoma: Benign disease presenting with hyperparathyroid crisis. Case Rep Med 2010: 596185, 2010.

55. Jayant M, Kaushik R, Kochar S and Attri AK: Giant parathyroid adenoma. Kathmandu Univ Med J (KUMJ) 9: 77-79, 2011.

56. Asghar A, Ikram M and Islam N: A case report: Giant cystic parathyroid adenoma presenting with parathyroid crisis after Vitamin D replacement. BMC Endocr Disord 12: 14, 2012.

57. Mazeh H, Sippel RS and Chen H: Three large, functioning cystic parathyroid adenomas. Endocr Pract 18: e14-e16, 2012.

58. Khan A, Khan Y, Raza S, Akbar G, Khan M, Diwan N and Rizvi W: Functional parathyroid cyst: A rare cause of malignant hypercalcemia with primary hyperparathyroidisma case report and review of the literature. Case Rep Med 2012: 851941, 2012.

59. Zaman MU, Fatima N and Sajjad Z: Giant cystic parathyroid adenoma with thrombosis of internal jugular vein seen on CT and Tc-99m methoxy isobutyl isonitrile parathyroid scan. Indian J Nucl Med 27: 122-123, 2012.

60. Suzuki K, Sakuta A, Aoki C and Aso Y: Hyperparathyroidism caused by a functional parathyroid cyst. BMJ Case Rep 2013: bcr2012008290, 2013. 
61. Sisodiya R, Kumar S, Palankar N and B V D: Case report on giant parathyroid adenoma with review of literature. Indian J Surg 75 (Suppl): S21-S22, 2013.

62. Dutta D, Selvan C, Kumar M, Datta S, Das RN, Ghosh S, Mukhopadhyay S and Chowdhury S: Needle aspirate PTH in diagnosis of primary hyperparathyroidism due to intrathyroidal parathyroid cyst. Endocrinol Diabetes Metab Case Rep 2013: 130019, 2013.

63. Kim MY, Chung CY, Kim JS, Myung DS, Cho SB, Park CH, Kim Y and Joo YE: Parathyroid cyst presenting as acute pancreatitis: Report of a case. Chonnam Med J 49: 125-128, 2013.

64. Haldar A, Thapar A, Khan S and Jenkins S: Day-case minimally invasive excision of a giant mediastinal parathyroid adenoma. Ann R Coll Surg Engl 96: e21-e23, 2014.

65. Salido S, Gómez-Ramírez J, Bravo JM, Martín-Pérez E, Fernández-Díaz G, Múñoz de Nova JL, Auza J and Larrañaga E: Parathyroid adenoma in third pharyngeal pouch cyst as a rare case of primary hyperparathyroidism. Ann R Coll Surg Engl 96: e8-e10, 2014

66. Kawashima ST, Usui T, Ueda Y, Kobayashi MK, Tsuiki M, Tanase-Nakao K, Nanba K, Tagami T, Naruse $M$, Watanabe Y, et al: Primary hyperparathyroidism due to atypical vertically long cystic adenoma. Endocrinol Diabetes Metab Case Rep 2014: 140086, 2014.

67. Garas G, Poulasouchidou M, Dimoulas A, Hytiroglou P, Kita M and Zacharakis E: Radiological considerations and surgical planning in the treatment of giant parathyroid adenomas. Ann R Coll Surg Engl 97: e64-e66, 2015.

68. Sumana B, Sabaretnam M, Sarathi V and Savith A: Functional parathyroid cystic adenoma: A rare cause of hypercalcemic crisis with primary hyperparathyroidism. Indian J Pathol Microbiol 58: 487-490, 2015

69. Colsa-Gutiérrez P, Kharazmi-Taghavi M, Pelayo-Salas Á and Ingelmo-Setién A: Cystic parathyroid adenoma: Report of a case. Acta Otorrinolaringol Esp 66: e28-e30, 2015 (In English, Spanish).

70. Dogan U, Koc U, Mayir B, Habibi M, Dogan B, Gomceli I and Bulbuller N: Life-threatening intrathyroidal parathyroid adenoma. Int J Clin Exp Med 8: 1501-1503, 2015.

71. Taghavi Kojidi H, Vagharimehr N, Mohseni S, Pajouhi M and Mohajeri-Tehrani MR: Unusual ectopic parathyroid adenoma: A case report. Acta Med Iran 54: 547-550, 2016.

72. Pecheva M, Mahendran K, Kadlec J, Lofthouse M and Van Tornout F: Mediastinal giant parathyroid adenoma-a minimally invasive mediastinal surgical approach for an emergency presentation. Ann Cardiothorac Surg 5: 70-73, 2016.

73. Krishnamurthy A, Raghunandan G and Ramshankar V: A rare case of giant parathyroid adenoma presenting with recurrent episodes of pancreatitis. Indian J Nucl Med 31: 36-38, 2016.

74. Taguchi T, Sugimoto T and Terada Y: Cystic parathyroid adenoma with intracystic hemorrhage. Endocrine 52: 399-400, 2016.

75. Sahsamanis G, Gkouzis K, Samaras S, Pinialidis D and Dimitrakopoulos G: Surgical management of a giant parathyroid adenoma through minimal invasive parathyroidectomy. A case report. Int J Surg Case Rep 31: 262-265, 2017.
76. Araujo Castro M, López AA, Fragueiro LM and García NP: Giant parathyroid adenoma: Differential aspects compared to parathyroid carcinoma. Endocrinol Diabetes Metab Case Rep 2017: 17-0041, 2017.

77. El-Housseini Y, Hübner M, Boubaker A, Bruegger J, Matter M and Bonny $\mathrm{O}$ : Unusual presentations of functional parathyroid cysts: A case series and review of the literature. J Med Case Rep 11: 333, 2017.

78. Ebrahimpur M, Mohajeri Tehrani MR and Pejman Sani M: Huge ectopic parathyroid adenoma. Arch Iran Med 21: 547-448, 2018.

79. Anagnostis P, Panagiotou A, Rafailidis S and Kita M: Coexistence of a large functioning parathyroid cyst with papillary thyroid carcinoma: A case report and review of the literature. Case Rep Womens Health 21: e00091, 2018.

80. Cayir D, Bozkurt M, Erdoğan M, Gültekin SS, Azili C and Türker A: Doughnut shaped parathyroid adenoma. Mol Imaging Radionucl Ther 28: 41-43, 2019.

81. Al-Hassan MS, Mekhaimar M, El Ansari W, Darweesh A and Abdelaal A: Giant parathyroid adenoma: A case report and review of the literature. J Med Case Rep 13: 332, 2019.

82. Wang A and Yuan L: Primary hyperparathyroidism. Clin Case Rep 7: 849-850, 2019.

83. Miller BJ, Isaacs K, Khan E and Palazzo FF: Transcervical excision of a giant mediastinal parathyroid adenoma. BMJ Case Rep 12: e228292, 2019.

84. Nastos C, Sotirova I, Paspala A, Dafnios N, Basios N, Dellaportas D, Vasileiou I and Peppa M: Giant ectopic retroesophageal parathyroid adenoma excised via cervical incision: A case report. Indian J Surg 83: 296-298, 2021.

85. Gücek Haciyanli S, Acar N, Gür EÖ, Çelik SC, Karaıslı S, Dilek ON and Haciyanli M: Severe hypercalcaemia of primary hyperparathyroidism: Could giant adenoma be the real culprit rather than carcinoma? Ann R Coll Surg Engl 102: 363-368, 2020.

86. Werner C, Lupp A, Mtuka-Pardon G, Kloos C, Wolf G, Aschenbach R, Biermann A, Freesmeyer M and Seifert P: Case report of a cystic parathyroidal adenoma with rapid growth induced by cinacalcet. BMC Endocr Disord 20: 53 , 2020.

87. Monsour EP, Rifai F, Chacko J, Hamza A and Abusaada K: A rare case of severe hypercalcemia secondary to atypical parathyroid cystic adenoma with negative sestamibi scan. Cureus 12: e6830, 2020.

88. Güneş SG, İbrahimov F, Uğurum Yücemen A, Yenigün BM and Enön S: Atypically located cystic parathyroid adenoma. Turk Gogus Kalp Damar Cerrahisi Derg 28: 217-218, 2020.

89. Krishnaraju VS, Saikia UN, Bhadada SK, Mittal BR, Sood A, Singh P, Dahiya D and Kumari P: Cystic parathyroid adenomas: An enigmatic entity and role of Tc-99 m sestamibi scintigraphy. Endocr Pract 27: 614-620, 2021.

90. Abdulsalam MS, Devanayagam S, Santosham R, Ganapathy V, Menon $\mathrm{M}$ and Simon S: Mediastinal parathyroid adenoma removal by video-assisted thoracoscopic surgery. Ann Afr Med 20: 150-153, 2021. 